May 2015

\title{
Sharpening the Search Saw: Lessons from Expert Searchers
}

Virginia M. Tucker

San Jose State University, virginia.tucker@sjsu.edu

Follow this and additional works at: https://scholarworks.sjsu.edu/ischoolsrj

Part of the Archival Science Commons, Cataloging and Metadata Commons, Collection Development and Management Commons, Information Literacy Commons, Scholarly Communication Commons, and the Scholarly Publishing Commons

\section{Recommended Citation}

Tucker, V. M. (2015). Sharpening the Search Saw: Lessons from Expert Searchers. School of Information Student Research Journal, 5(1). https://doi.org/10.31979/2575-2499.050102 Retrieved from https://scholarworks.sjsu.edu/ischoolsrj/vol5/iss1/2

This article is brought to you by the open access Journals at SJSU ScholarWorks. It has been accepted for inclusion in School of Information Student Research Journal by an authorized administrator of SJSU ScholarWorks. For more information, please contact scholarworks@sjsu.edu. 


\section{Sharpening the Search Saw: Lessons from Expert Searchers}

\section{Keywords}

online searching, citation searching, controlled vocabulary

\section{About Author}

Virginia M. Tucker, MLS, PhD, is on the faculty at the School of Information, San José State University 


\section{Introduction}

Many students consider themselves to be proficient searchers and yet are disappointed or frustrated when faced with the task of locating relevant scholarly articles for a literature review. This bleak experience is common among higher education students, even for those in library and information science programs who have heightened appreciation for information resources and yet may settle for "good enough Googling" (Plosker, 2004, p. 34). This is in large part due to reliance on web search engines that have evolved relevance ranking into a vastly intelligent business, one in which we are both its customers and product (Vaidhyanathan, 2011). Google's Hummingbird nest of search algorithms (Sullivan, 2013) provides quick and targeted hits, yet it can trigger blinders-on trust in first-page results.

Concern for student search practices ranges from this permissive trust all the way to lost ability to recall facts and formulate questions (Abilock, 2015), lack of confidence in one's own knowledge (Carr, 2010), and increased dependence on single search boxes that encourage stream-of-consciousness user input (Tucker, 2013); indeed, students may be high in tech savvy but lacking the critical thinking skills needed for information research tasks (Katz, 2007). Students have come to rely on web search engine intelligence - and it is inarguably colossal - to such an extent that they may fail to formulate a question before charging forward to search for its answer. "Google is known as a search engine, yet there is barely any searching involved anymore. The gap between a question crystallizing in your mind and an answer appearing at the top of your screen is shrinking all the time. As a consequence, our ability to ask questions is atrophying" (Leslie, 2015, para. 4). Highly accomplished students often lament their lack of skills for higher-level searching that calls for formulating pointed questions when struggling to develop a solid literature review.

In addition, many are unaware that search results are filtered based on previous searches, location, and other factors extracted from personal search patterns by the search engine. Two students working side by side and entering the same search terms may receive quite different results on Google, yet the extent to which this 'filter bubble' (Pariser, 2011) is personalizing their search results is difficult to assess and to overcome. Just as important, it can be impossible to know what a search might be missing: how to know what's not there? This portrayal of the information landscape may appear gloomy but, in fact, it could not be a more inspiring environment in which to do research, to find connections in ideas, and to benefit from and generate new ideas. A few lessons from expert searchers, focused on critical concepts and search practices, can sharpen a student's search saw and move the proficient student-researcher, desiring more relevant and comprehensive search results, into a trajectory toward search expertise.

For the lessons involved in this journey, the focus is on two areas: first, the critical conceptscalled threshold concepts (Meyer \& Land, 2003) — found to be necessary for developing search expertise (Tucker et al., 2014); and, second, four strategic areas within search that can have significant and immediate impact on improving search results for research literature. The latter are grounded in the threshold concepts and positioned for application to literature reviews for graduate student studies.

\section{Literature Reviews \& Searching}

The abbreviated lessons described here are a brief introduction to what experienced searchers do; the intention is to introduce ways that can dramatically improve both the search outcome for a literature review and the searcher's experience, and to provide ideas for further exploration. The focus is on strategies that have generated the most 'ah-ha' moments for my students and that have been borne out as critical knowledge by research into the search practices of experts and professional searchers (Tucker, 2012). In addition, the strategy areas are only being highlighted and further discussion, practice, and reflection would be necessary for them to be integrated into a searcher's understanding and praxes. For example, in my classes, search assignments include considerable hands-on search time, documenting the search plan and steps tried, and then reflecting on the experiences. A typical comment from a student completing the class is: "I wish that I'd taken this class earlier, but it certainly helped me throughout this semester with my research methods class and its literature review." A literature review supports critical 
objectives in the research process and its development has multiple stages, some of which are the searching of scholarly databases: "a literature review performs two functions: first, to frame and ground one's discovery, analysis, and synthesis of the relevant secondary literature produced by scholars about a particular topic; and two, to inaugurate new questions, concerns, and inquiry beyond what we already know" (Bernier, 2011, p. 2).

My own grounding of this article includes the experiences from teaching a graduate course in online searching for the last ten years to students preparing for careers in the information profession. This means they will be conducting their own research and also playing a role in the research and information experiences of others, calling for an understanding of and facility for searching literature that can be conveyed to others as well (Tucker, 2014).

\section{Lesson 1: Threshold concepts for search expertise}

Many articles cover tools for improving search results (Bell, 2007); however, tools alone fall short of the lessons we can learn from expert searchers who, while certainly adept with search tools, also have a profound understanding of search concepts and the information environment. Threshold concept theory (Meyer \& Land, 2003) provides a framework for these critical concepts which are "key ideas, often troublesome and counter-intuitive, that are critical to profound understanding of a domain. Once understood, they allow mastery of significant aspects of the domain" (Tucker et al., 2014). For search expertise, four threshold concepts have been identified:

Information environment: the total information environment is perceived and understood;

Information structures: content, index structures, and retrieval algorithms are understood;

Information vocabularies: fluency in search behaviours related to language, including natural language, controlled vocabulary, and finesse using proximity, truncation, and other languagebased tools. The fourth threshold concept is Concept fusion, the integration of the other three threshold concepts and further defined by additional properties. (Tucker, 2015, chapter 7) Interestingly, in this study there were student participants with only a few years of experience who demonstrated more expertlike search practices than some of the professional searchers with over 25 years' experience who were exceptionally good tool users. The difference lay in the depth of understanding of concepts and the ability to combine these concepts in the moment, one manifestation of concept fusion, which had the additional properties of: visioning (anticipating next moves), being light on one's 'search feet' (dancing property), and profound ontological shift (identity as searcher).

Threshold concepts are being studied in a host of academic disciplines to support the exploration of curriculum and its redesign; they have recently been the framework for a reworking of the information literacy standards of the Association of College and Research Libraries (ACRL, 2015).

\section{Lesson 2: Four strategies for search expertise}

This lesson zeroes in on four elements of search strategy that can have significant impact on improving both the quality of search results and the searcher's information experience: operators and limiters, pearl growing, controlled vocabulary, and citation tracing. There are many more strategies and tools, of course, and these four have been carefully selected for impact factor.

When searching for the most relevant literature it is rare to hit one out of the park on the first atbat, and yet this is a pattern for some students, easily exacerbated by procrastination and 'just Google it' habits, search habits that may satisfice but are not up to the rigor needed for a literature review. As mentioned earlier, studies show that searchers often stop after perusing the first page of results from a web search (Edwards \& Bruce, 2006, p. 352). A further barrier to developing search expertise is that students need help to "overcome their habituation with past experiences of having been "taught to the test'; they tend to look for right-answer recipes, creating barriers to learning experiences that engage threshold knowledge" (Tucker, 2015, chapter 7).

One-step searching is not sufficient because research is iterative and searching for a research purpose is likewise iterative. A quick Google search may work well for a factual look-up (a 'known 
item' search) but developing a literature review requires planning as well as flexibility, paying attention to the results that unfold; these early steps in the search experience are exploratory and essential (Kuhlthau, 1991; 2015). The entire experience can be viewed through the lens of the berrypicking model (Bates, 1989) but, as search expertise is developing, there is a qualitatively deeper understanding of the berry and bush environment: the expert searcher "understands how the berries came to grow on the bush, why they grew where they did, where there might be clusters of berries hidden away under foliage, and even who planted the bush, tended it, amended the soil, and how this impacted its growth and harvest. This profound knowledge is integrative and impacts the searcher's decisions and activities before, during, and after a search" (Tucker et al., 2014). The following search tools and strategies can help develop this knowledge base.

\section{- Use operators \& limiters}

Most students know about Boolean operators AND, OR, and NOT, but AND is just the first step toward mastering the art of word proximity operators. Commercial search engines provide operators to specify that words be in the same paragraph, same sentence, same field, or within a certain number of words from each other (near). In addition, it can be critically important to use field limiters for the best search outcome: to focus results, take advantage of limiters for searching only in the title, subject term, and/or abstract field, as a simple illustration. On Google, the site: limiter and date range limiters are two of the most useful options for adding relevance to results. On a commercial search engine, to limit retrieval to the fields that are most indicative of the subject content of articles, it is usually possible to group multiple limiters and, for example, to search the title, subject indexing, lead paragraph, and abstract fields together. A search for TI, SU,LP,AB= (adolescent diabetes) will produce more focused and relevant results than an unrestricted keyword search on adolescent diabetes that retrieves from anywhere in the text, even an article with a cursory mention in the $34^{\text {th }}$ paragraph.

\section{- Grow the pearl}

One of the easiest ways to improve on a search and retrieve additional relevant records is to examine the records resulting from a preliminary strategy. This searching style is called pearl growing -it might be thought of as "take what you like and get more like it." If you are having trouble thinking of synonyms or alternative terms for a topic, try starting out with just keywords for the ideas you already have. Even if you locate only a few records from this initial strategy, display them so that you can see the controlled vocabulary terms. (In fact, search engines with a built-in "more like this" feature are often using controlled vocabulary terms or intelligent tagging behind the scenes to generate the related documents displayed.) This approach works well to locate authors writing on the topic; then use the author name as a pearl to find similar works.

\section{- Enlist controlled vocabulary terms}

One of the most common mistakes by searchers who are new to scholarly databases is to rely solely on keywords (natural language terms) when searching; knowing when to use keywords vs. controlled vocabulary — and being flexible about it —is part of acquiring expertise in searching (Tucker, 2012). The 'when' can depend on: “1) the database, 2) the vocabulary itself and the indexing policies that dictate how it is applied, 3) the topic to be searched, 4) the requester" (Tenopir, 1987, p. 58). In addition, controlled vocabulary may appear in different fields in documents, most often as subject headings but, in some databases, as classification codes or authority terms, such as standardized drug or chemical names. Search results will suffer if the controlled vocabulary term is not used. An online thesaurus will help with navigating the vocabulary and locating best terms for a topic, but not all databases have a thesaurus; if no thesaurus, see the recommendations above about growing the pearl. 


\section{- Trace citations, back \& forward in time}

Citation-based connections can provide search access where vocabulary-based methods cannot go. If an author cites another author's work, this indicates the two are closely related. Many students are in the habit of looking at a useful article's bibliography to see if there are additional relevant publications to be found here-but this will always find only older materials. Citation searching makes it possible to go forward in time from that same useful article, to locate articles that have cited it since it was published. Mann refers to citation searching as "the mirror image of footnote chasing" (2015, p. 141). Particularly when you find a 'pearl' of an article, running a citation search on it is good practice. Web of Science ${ }^{\mathrm{TM}}$ provides citation search tools for this purpose as well as more advanced tools for citation mapping, identifying core literature on a narrow or broad topic, and methods for generating metrics to help in assessing if a particular idea or topic niche is worth pursuing further.

\section{Conclusion}

This article has presented short lessons from expert searchers on critical concepts—called threshold concepts-along with a small handful of search strategy tools that can have big impact for studentresearchers for sharpening the search saw. There is much more to learn-many more lessons from experts-and learning new search habits takes practice. The intention has been to provide strategic ideas to help with searching for scholarly literature and additional ideas to be explored for moving toward search expertise. 


\section{References}

Abilock, D. (2015). Addition friction: How to design deliberate thinking into the research process. Library Media Connection, 33(4), 33.

Association of College and Research Libraries (ACRL). (2015, February). Framework for Information Literacy for Higher Education. Retrieved from http://www.ala.org/acrl/standards/ilframework

Bates, M.J. (1989). The design of browsing and berrypicking techniques for the online search interface. Online Review, 13(5), 407-424.

Bell, S. (2007). Tools every searcher should know and use. Online, 31(5), 22-27.

Bernier, A. (2011). Reaching escape velocity and the purpose of SLIS. Student Research Journal. Student Research Journal, 1(1).

Carr, N. (2010). The shallows: What the internet is doing to our brains. New York: W.W. Norton.

Detmering, R. \& Johnson, A.M. (2011). Focusing on the thinking, not the tools: Incorporating critical thinking into an information literacy module. Journal of Business \& Finance Librarianship, 16(2), 101-107.

Edwards, S.L. \& Bruce, C.S. (2006). Panning for gold: Understanding students' information searching experiences. In C.S. Bruce, G. Mohay, G. Smith, I. Stoodley, \& R. Tweedale (Eds.), Transforming IT education: Promoting a culture of excellence (pp. 351-369). Santa Rosa, CA: Informing Science Press.

Katz, I. R. (2007). ETS research finds college students fall short in demonstrating ICT (information and communication technology) literacy. College \& Research Libraries News, 68(1), 35-37.

Kuhlthau, C.C. (1991). Inside the search process: Information seeking from the user's perspective. Journal of the American Society for Information Science, 42(5), 361-371.

Kuhlthau, C.C. (2015). Model of the information search process (ISP). Retrieved from http://comminfo.rutgers.edu/ kuhlthau/information_search_process.htm

Leslie, I. (2014, October 12). Google makes us all dumber: The neuroscience of search engines. Salon.com. Retrieved from http://www.salon.com

Mann, T. (2015). Oxford guide to library research, $4^{\text {th }}$ edition. New York: Oxford University Press.

Meyer, J.H.F. \& Land, R. (2003). Threshold concepts and troublesome knowledge (1): Linkages to ways of thinking and practising within the disciplines. In C. Rust (Ed.) Improving student learning: Ten years on (pp. 1-16). Oxford University Press. Originally published as ETL Occasional Report 4. Retrieved from http://www.etl.tla.ed.ac.uk/publications.html 
Pariser, E. (2011). The filter bubble: How the new personalized web is changing what we read and how we think. New York: Penguin Press.

Plosker, G. (2004). Making money as an aggregator. Online, 28(2), 34-38.

Sullivan, D. (2013, September 26). All about the new Google Hummingbird algorithm. SearchEngineLand.com. Retrieved from http://www.searchengineland.com

Tenopir, C. (1987). Searching by controlled vocabulary or free text. Library Journal, 112, 58-59.

Tucker, V.M. (2012). Acquiring search expertise: Learning experiences and threshold concepts. Ph.D. dissertation, Queensland University of Technology, Brisbane, Australia.

Tucker, V.M. (2013, November). The expert searcher and threshold concepts. School of Information Colloquium Series, San José State University. Retrieved from https://ischoolapps.sjsu.edu/blogs/ colloquia/?p=997

Tucker, V.M. (2014). The expert searcher's experience of information. In C.S.Bruce, K.Davis, H.Hughes, H.Partridge, \& I.Stoodley (Eds.), Information experience: Approaches to theory \& practice, (pp. 239-255). Bingley, UK: Emerald Group Publishing.

Tucker, V.M. (2015, in press). Learning experiences and the liminality of expertise. In R.Land, H.F Meyer, \& M.T. Flanagan, (Eds.), Threshold concepts in practice, Chapter 7. Rotterdam: Sense Publishers.

Tucker, V.M., Weedman, J., Bruce, C.S., \& Edwards, S.L. (2014). Learning portals: Analyzing threshold concept theory for LIS education. Journal of Education for Library \& Information Science, 55(2), 150-165.

Vaidhyanathan, S. (2011). The Googlization of everything and why we should worry. Berkeley, CA: University of California Press. 